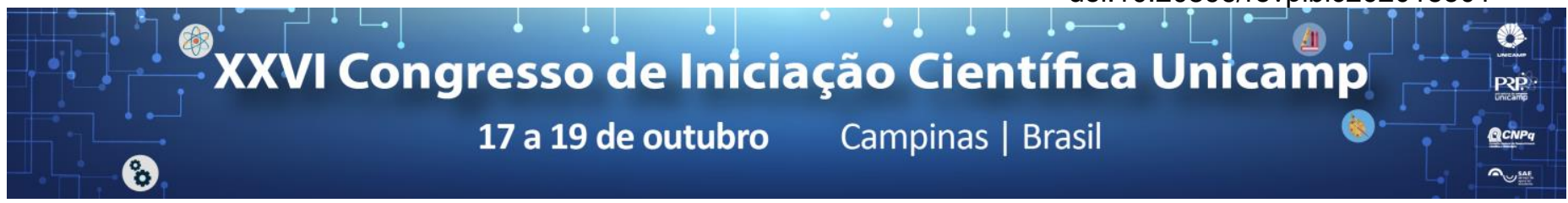

\title{
COMPLEMENTARIDADE E PADRÕES DE COMÉRCIO ENTRE ECONOMIAS DO MERCOSUL
}

\section{Bolsista: Gabriela Borges Henriques; Orientador: Marco Antonio Rocha.}

\section{Resumo}

A pesquisa procurou analisar a evolução dos padrões de comércio no interior do bloco regional do Mercosul. A análise foi realizada cobrindo o período de 1995 até 2010, buscando apresentar a evolução do comércio bilateral entre os países do bloco em termos de sua complementariedade. $\mathrm{O}$ trabalho, deste modo, procura demonstrar em que cadeias produtivas houve avanços em termos da integração comercial dentro do bloco regional. Foram utilizados índices de intensidade comercial (DRYSDALE \& GARNAUT, 1982; KIM, 2013) para analisar se ao longo do período estudado houve especialização comercial entre as economias do Mercosul. A hipótese inicial é que acordos de integração comercial devem gerar aumentos nos índices de complementariedade comercial, como forma de ampliar o grau de especialização de cada economia integrante do acordo.

\section{Palavras-chave: \\ Comércio Internacional; Economia Internacional; Mercosul.}

\section{Introdução}

Os indicadores de complementaridade comercial permitem analisar se há sobreposição ou não de produtos na pauta comercial bilateral entre países a partir da classificação geral das mercadorias na base de dados utilizada (UN COMTRADE). Desta forma, possibilita analisar a existência de algum padrão de especialização entre países selecionados e avaliar o grau de convergência da estrutura comercial dessas economias em seus principais produtos transacionados.

Entende-se que o processo de integração regional deve se converter na formação de padrões de especialização que permitam o crescimento das escalas produtivas de parte do conjunto de indústrias das economias envolvidas. Portanto, o padrão desejável seria aquele em que os índices de intensidade comercial - baseados no conceito de complementariedade - apresentassem acréscimos ao longo do tempo. A decomposição do índice de complementaridade utilizada foi:

$$
c_{i j}=\sum_{K}\left(\frac{M_{w}^{K}}{M_{w}}\right) S_{i}^{K} \cdot R_{j}^{K}
$$

$$
\text { Tal que, } \mathrm{S}_{\mathrm{i}}^{\mathrm{K}}=\frac{\frac{\mathrm{x}_{\mathrm{i}}^{\mathrm{K}}}{\mathrm{X}_{\mathrm{i}}} / \frac{\mathrm{x}_{\mathrm{w}}^{\mathrm{K}}}{\mathrm{x}_{\mathrm{w}}} \text { e }}{\mathrm{k}} \mathrm{R}_{\mathrm{j}}^{\mathrm{k}}=\frac{\mathrm{M}_{\mathrm{j}}^{\mathrm{K}}}{\mathrm{M}_{\mathrm{j}}} / \frac{\mathrm{M}_{\mathrm{w}}^{\mathrm{K}}}{\mathrm{M}_{w}} \text {, isto é, a margem }
$$

do país i nas exportações totais do produto $\mathrm{K}$ e a margem das importações do país j nas importações totais do produto $\mathrm{K}$.

O grau de especialização comercial dos países i e j pode ser obtido através do desvio padrão da estrutura de vantagem comparativa de cada país.

$$
\begin{aligned}
& \sigma^{2}\left(S_{i}\right)=\sum_{K}\left(\frac{X_{W}^{K}}{X_{w}}\right) \cdot\left(S_{i}^{K}-1\right)^{2} \\
& \sigma^{2}\left(R_{j}\right)=\sum_{K}\left(\frac{X_{W}^{K}}{X_{W}}\right) \cdot\left(R_{j}^{K}-1\right)^{2}
\end{aligned}
$$

O grau de complementaridade entre o país i e o país j pode então ser definido a partir da covariância dos índices de especialização de exportação do país i e de importação do país j, tal que:

$$
\begin{aligned}
& \operatorname{cov}\left(S_{i}, R_{j}\right)=\sum_{K}\left(\frac{X_{W}^{K}}{X_{W}}\right)\left(S_{i}^{K}-1\right)\left(R_{j}^{K}-1\right) \\
& \operatorname{Com}, \\
& C_{i j}=\operatorname{coV}\left(S_{i}, R_{i}\right)+1
\end{aligned}
$$

\section{Resultados e Discussão}

Ainda que de forma preliminar, alguns resultados já demonstram que houve baixa integração comercial entre as economias do Mercosul. Os resultados mais positivos encontram-se extremamente localizados em algumas cadeias produtivas ligadas à produção de bens de consumo duráveis e certos gêneros alimentícios.

Comparando os valores dos índices analisados com aqueles obtidos em estudos semelhantes para outros blocos regionais, observa-se que, sobretudo quando comparado ao padrão asiático, as cadeias produtivas da América do Sul são muito pouco integradas. Em termos comparativos, o papel regional do Brasil em termos de liderança comercial, isto é, país com maior intensidade comercial com os demais da região, ainda se encontra muito pouco desenvolvida.

\section{Conclusões}

O estudo discute dados sobre o quão pouco evoluiu a integração comercial no interior do bloco regional. Os dados refletem a ausência de políticas de integração produtiva ou da capacidade de alguma economia da região exercer liderança em um processo de integração regional.

\footnotetext{
1 Drysdale, P. \& Garnaut, R. Trade intensities and the analysis of bilateral trade flows in a many-country world: a survey. Hitotsubashi Journal of Economics, 1982, 22(2): 62-84.

2 Kim, S. J. Trade complementarity between South Korea and her major trading countries: its changes over the period of 2005-2009. World Review of Business Research, 2013, 3(2): 64-83.
} 